\title{
Normative reference ranges for echocardiographic chamber dimensions in a healthy Central European population: results from the Czech post-MONICA survey
}

Josef Marek', Jean-Claude Lubanda', Renata Cifkova, ${ }^{1,2}$, Petr Kuchynka', Lubor Golan', Eduard Nemcek and Ales Linhart ${ }^{1 *}$ (D)

\begin{abstract}
Background: Normative reference values for echocardiographic chamber quantification are of great importance; however, this can be challenging. Our aim was to derive these values including degrees of abnormality from a random Central European population sample with a homogeneous subset of healthy subjects.

Methods: We analysed echocardiograms obtained in a randomly selected population sample during the Czech post-MONICA survey in 2007/2008. Overall, 1850 out of 2273 persons of the whole sample of three districts had adequate echocardiograms (81.4\%). A healthy subgroup defined by the absence of known cardiovascular disease was used to define normal reference range limits ( $n=575$, median age 42 years [IQR 34-52], 57\% females). The whole population sample with predefined percentile cut-offs was used to define degrees of abnormality.

Results: Left ventricular (LV) size tended to decrease with age, while LV mass increased with age in both males and females and in both the healthy and general populations. LV dimensions were larger in males, except for body surface area-indexed LV diameter. M-mode derived LV measurements were larger and LV mass higher compared to 2D measurements. Right ventricle basal dimension was larger in males.

Conclusions: Our study provides reference ranges for echocardiographic measurements obtained in a healthy subgroup derived from an epidemiological study of a Central European population. Where feasible, degrees of abnormality are provided based on the whole population sample including patients with disease. Our data show that age, gender and measurement method significantly affect cardiac dimensions and function and should be always taken into account.
\end{abstract}

Keywords: Echocardiography, Left ventricular function, Left ventricular mass, Left ventricular end-diastolic dimension, Right ventricular function, Atrium

\section{Introduction}

Echocardiography is the most commonly used imaging method to evaluate cardiac structure and function [1]. Quantification of cardiac chamber dimensions and function remains paramount to echocardiographic examination, defining normal values is thus of great importance.

\footnotetext{
* Correspondence: alinh@lf1.cuni.cz

²nd Department of Medicine - Department of Cardiovascular Medicine, First Faculty of Medicine, Charles University and General University Hospital in Prague, U Nemocnice 2, 12808 Praha 2, Czech Republic

Full list of author information is available at the end of the article
}

However, this can be challenging due to variations based on gender, age and specific populations. Indeed, recent data show substantial influences of ethnicity, gender and age, while only limited epidemiological data exist uniquely for Central European populations [2, 3]. Furthermore, with a healthy population, only normal reference limits can be reliably calculated. For defining degrees of abnormality, a true general population sample is advantageous $[4,5]$. Therefore, we aimed to define normal chamber dimensions and function based on a randomly selected population sample in the Czech Republic. 


\section{Methods}

\section{Study population}

The Czech post-MONICA study is a population-based survey assessing cardiovascular risk profile in a randomly selected sample of the Czech population. Detailed methods of the study have been described previously [6, 7]. Briefly, one-percent adult population samples stratified by age and gender were randomly selected from the general population of nine districts of the country. Selection was made using the General Health Insurance Company registry that keeps, by law, a list of people who are insured. Since health insurance is mandatory for Czech citizens, the registry covers the entire population. Echocardiographic examination was performed in three districts (Benesov, Pardubice, and city of Pilsen). The present analysis includes 1850 individuals (i.e. $81.4 \%$ of the entire screened population, $n=2273$, within the three districts in 2007/2008) over 25 years of age in whom echocardiograms were available and these scans were used for subsequent analysis. The study was approved by the joint ethics committee of the Institute for Clinical and Experimental Medicine and Thomayer Hospital and was in accordance with the Declaration of Helsinki.

As Fig. 1 shows, the healthy cohort was defined as a subset of the general sample without obesity $\left(\mathrm{BMI}>30 \mathrm{~kg} / \mathrm{m}^{2}\right)$, arterial hypertension, known cardiovascular disease, renal dysfunction, diabetes mellitus, thyroid disorder, lipid-lowering or corticosteroid treatment. The healthy cohort included 575 selected patients. The total cohort consisted of all the recruited individuals irrespective of treatment or comorbidities.

\section{Echocardiography}

All studies were done using the GE Vivid 7 system (GE Healthcare, Chicago, Illinois, USA). Three measurements were taken for each parameter and averaged. All measurements were done according to the recommendations for ASE/EACVI chamber quantification unless otherwise specified [4] and were done in one centralized core laboratory. Briefly, aortic root and left atrial (LA) diameters were measured from the parasternal long-axis view using $\mathrm{M}$-mode and both measurements were performed using the leading edge to leading edge convention.

Left ventricular (LV) dimensions were measured first using 2D guided M-mode acquisition, with diameters measured according to the ASE convention [1]. The interventricular septum and posterior wall thickness and $\mathrm{LV}$ diastolic diameter were also measured with the $2 \mathrm{D}$ technique using the blood-myocardial interface. LV mass

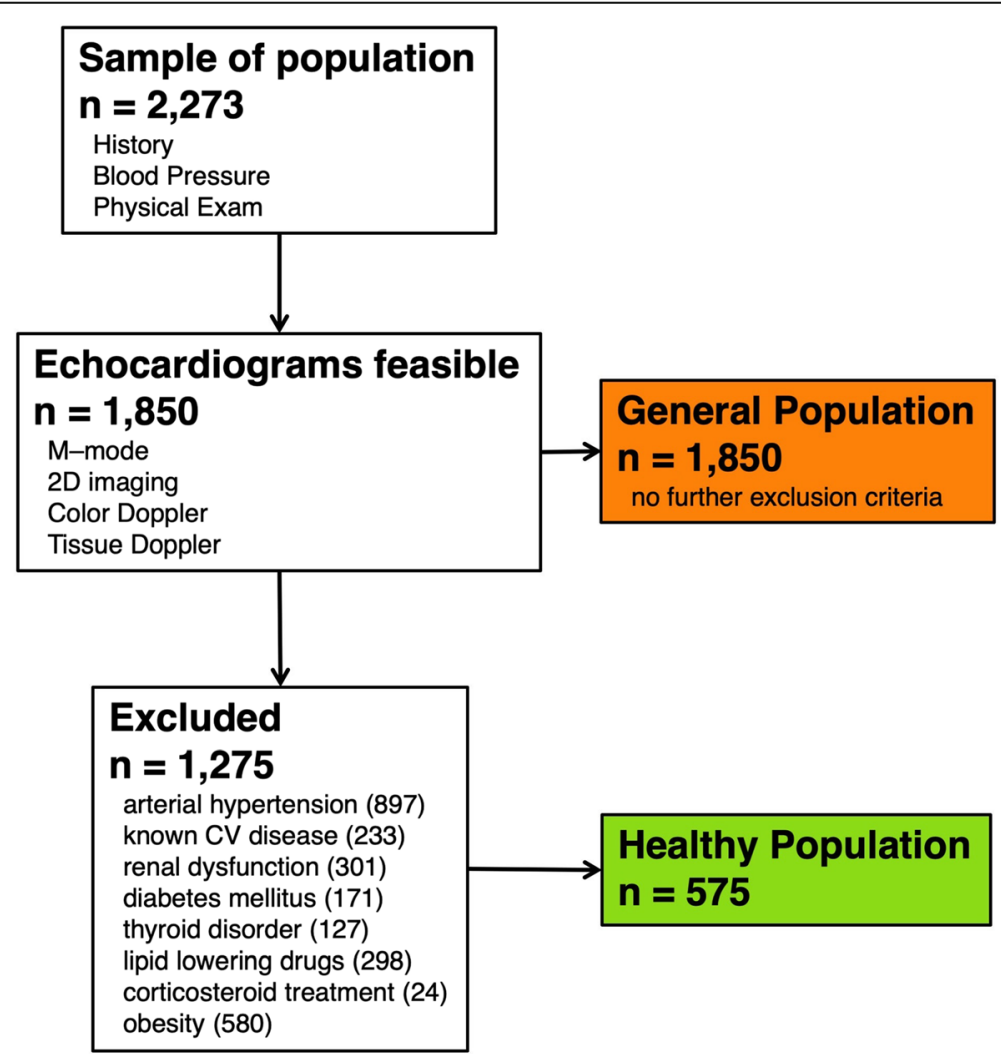

Fig. 1 Flowchart showing selection of patients for the present study. The population was randomly selected from the country's three districts as part of the Czech post-MONICA study 2007-2008. CV, Cardiovascular. The numbers in parentheses indicate amount of patients that were excluded for that specific reason 


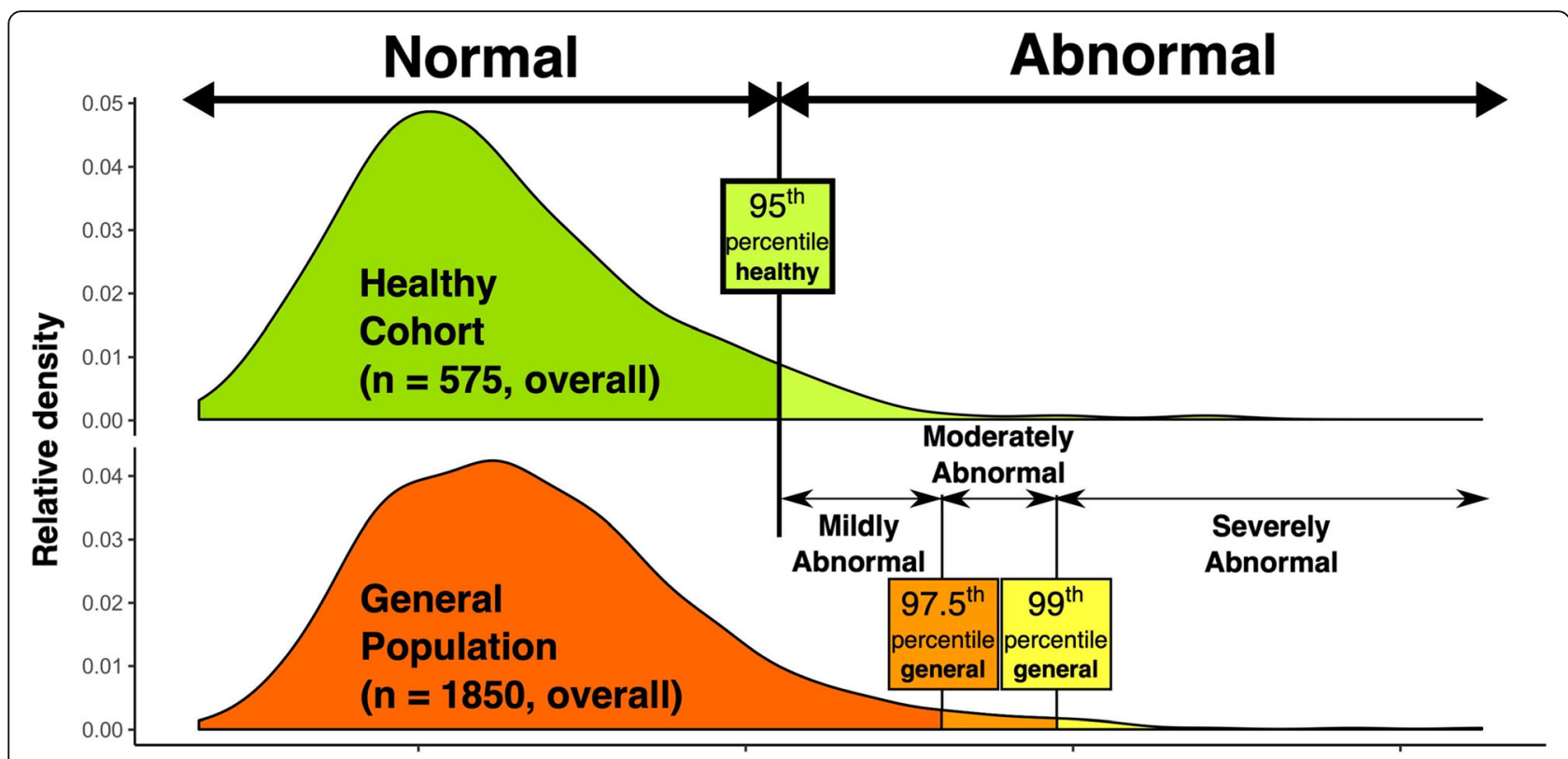

\section{Variable distribution}

Fig. 2 Illustration showing definition of reference ranges. Upper part of the figure shows distribution in healthy individuals, with the 95th quantile used to define abnormal value. Lower part of the figure shows the ways for defining different degrees of abnormality. Patients falling above the 95 th percentile of the healthy population but under the 97.5th percentile of the general population were classified as mildly abnormal; those between the 97.5th and 99th percentiles of the general population as moderately abnormal and patients over the 99th percentile of the general population as severely abnormal. The actual distribution density of this illustration was based on LV atrial volume distribution in males (indexed to BSA). BSA, body surface area; LV, left ventricle

Table 1 Baseline characteristics

\begin{tabular}{|c|c|c|c|}
\hline Variable & $\begin{array}{l}\text { Healthy subset } \\
n=575\end{array}$ & $\begin{array}{l}\text { Remaining cohort } \\
n=1275\end{array}$ & $p$ value \\
\hline Age (years) & $42[34,52]$ & $58[49,65]$ & $<0.001$ \\
\hline Female gender, n (\%) & $328(57 \%)$ & $631(49 \%)$ & 0.003 \\
\hline $\mathrm{BSA}\left(\mathrm{m}^{2}\right)$ & $1.82[1.70,1.99]$ & $1.97[1.82,2.13]$ & $<0.001$ \\
\hline Weight (kg) & $72[62,81]$ & $86[74,98]$ & $<0.001$ \\
\hline Height (cm) & $171[165,179]$ & $171[163,177]$ & 0.003 \\
\hline BMI $\left(\mathrm{kg} / \mathrm{m}^{2}\right)$ & $24[22,26]$ & $29[26,33]$ & $<0.001$ \\
\hline Systolic blood pressure (mmHg) & $118[109,124]$ & $132[121,144]$ & $<0.001$ \\
\hline Diastolic blood pressure (mmHg) & $78[72,81]$ & $83[78,90]$ & $<0.001$ \\
\hline History of CVD, n (\%) & & $230(18 \%)$ & \\
\hline Antihypertensive medication, n (\%) & & $606(48 \%)$ & \\
\hline Diabetes mellitus, n (\%) & & $171(13 \%)$ & \\
\hline Lipid-lowering drugs, n (\%) & & $298(23 \%)$ & \\
\hline Total serum cholesterol (mmol/l) & $5.02[4.42,5.71]$ & $5.25[4.57,5.92]$ & $<0.001$ \\
\hline Total serum triglycerides (mmol/l) & $0.97[0.73,1.39]$ & $1.39[1.03,2.02]$ & $<0.001$ \\
\hline HDL cholesterol (mmol/l) & $1.51[1.27,1.76]$ & $1.34[1.10,1.62]$ & $<0.001$ \\
\hline LDL cholesterol (mmol/l) & $2.94[2.37,3.58]$ & $3.05[2.41,3.65]$ & 0.091 \\
\hline Age group (n) & & & $<0.001$ \\
\hline under 40 years & 239 & 160 & \\
\hline $40-60$ years & 283 & 556 & \\
\hline over 60 years & 53 & 559 & \\
\hline
\end{tabular}

Continuous variables presented as median [25th, 75th percentile]

$B M I$ body mass index, BSA body surface area, CVD cardiovascular disease 
Table 2 Effects of age and gender on reference limits - left ventricle

\begin{tabular}{|c|c|c|c|c|}
\hline Variable & Age effect (per 10 years) & $\begin{array}{l}\text { Age effect } \\
p \text { value }\end{array}$ & Gender effect (male vs. female) & $\begin{array}{l}\text { Gender effect } \\
p \text { value }\end{array}$ \\
\hline \multicolumn{5}{|l|}{ Left ventricular dimensions } \\
\hline \multicolumn{5}{|l|}{ 2D method } \\
\hline LV end-diastolic diameter (mm) & $-0.7[-1.0,-0.3]$ & 0.001 & $5.6[4.3,7.0]$ & $<0.001$ \\
\hline LV end-diastolic diameter, BSA $\left(\mathrm{mm} / \mathrm{m}^{2}\right)$ & $-0.4[-0.8,-0.1]$ & 0.021 & $-1.4[-2.5,-0.4]$ & 0.007 \\
\hline \multicolumn{5}{|l|}{ M-mode method } \\
\hline LV end-diastolic diameter (mm) & $0.5[-0.1,1.2]$ & 0.113 & $5.4[4.0,6.8]$ & $<0.001$ \\
\hline LV end-diastolic diameter, BSA $\left(\mathrm{mm} / \mathrm{m}^{2}\right)$ & $0.3[-0.1,0.7]$ & 0.107 & $-1.3[-2.1,-0.4]$ & 0.004 \\
\hline LV end-systolic diameter (mm) & $0.7[-0.2,1.6]$ & 0.114 & $4.1[1.9,6.2]$ & $<0.001$ \\
\hline LV end-systolic diameter, BSA (mm/m²) & $0.4[-0.1,0.9]$ & 0.109 & $-0.4[-1.5,0.7]$ & 0.469 \\
\hline \multicolumn{5}{|l|}{ LV mass and wall thickness } \\
\hline \multicolumn{5}{|l|}{ 2D method } \\
\hline Interventricular septum (mm) & $0.5[0.1,0.8]$ & 0.011 & $1.3[0.4,2.3]$ & 0.004 \\
\hline LV Posterior wall (mm) & $0.4[0.2,0.6]$ & $<0.001$ & $1.5[1.0,2.0]$ & $<0.001$ \\
\hline LV mass, BSA $\left(\mathrm{g} / \mathrm{m}^{2}\right)$ & $4.2[2.1,6.4]$ & $<0.001$ & $23.5[18.4,28.6]$ & $<0.001$ \\
\hline \multicolumn{5}{|l|}{ M-mode method } \\
\hline Interventricular septum (mm) & $0.6[0.3,0.9]$ & $<0.001$ & $1.7[0.9,2.5]$ & $<0.001$ \\
\hline LV Posterior wall (mm) & $0.6[0.4,0.8]$ & $<0.001$ & $1.6[1.1,2.0]$ & $<0.001$ \\
\hline LV mass, BSA $\left(\mathrm{g} / \mathrm{m}^{2}\right)$ & $7.1[3.2,11.1]$ & $<0.001$ & $22.6[10.6,34.5]$ & $<0.001$ \\
\hline LV mass, height ${ }^{2.7}(\mathrm{~g} / \mathrm{m})$ & $4.2[2.2,6.2]$ & $<0.001$ & $4.8[-0.2,9.8]$ & 0.060 \\
\hline \multicolumn{5}{|l|}{ LV volumes and function } \\
\hline LV end-diastolic volume (ml) & $-6.6[-10.0,-3.1]$ & $<0.001$ & $35.4[25.1,45.6]$ & $<0.001$ \\
\hline LV end-diastolic volume, BSA ( $\left.\mathrm{ml} / \mathrm{m}^{2}\right)$ & $-3.1[-6.5,0.4]$ & 0.081 & $8.4[0.9,16.0]$ & 0.029 \\
\hline LV end-systolic volume (ml) & $-3.6[-5.0,-2.1]$ & $<0.001$ & $23.2[19.4,27.0]$ & $<0.001$ \\
\hline LV end-systolic volume, BSA (ml/m²) & $-2.1[-3.5,-0.8]$ & 0.002 & $6.4[2.9,9.9]$ & $<0.001$ \\
\hline LV ejection fraction (\%) & $1.4[-0.1,2.9]$ & 0.059 & $-1.6[-5.7,2.6]$ & 0.455 \\
\hline Mitral septal s' (cm/s) & $-0.2[-0.4,-0.1]$ & 0.001 & $-0.1[-0.4,0.3]$ & 0.658 \\
\hline Mitral lateral s' (cm/s) & $-0.3[-0.5,-0.1]$ & 0.002 & $0.4[-0.1,0.8]$ & 0.162 \\
\hline
\end{tabular}

Values depict effect size on reference limit (95th or 5th percentile of the healthy subset) with $95 \%$ confidence interval $B S A$ body surface area, $L V$ left ventricle

was calculated using the modified Devereux formula, from both $\mathrm{M}$-mode and $2 \mathrm{D}$ recordings as previously described [8].

LV volumes and ejection fraction were measured from the single plane apical four-chamber view using the Simpson rule. Left atrium (LA) volume was measured using the area-length method while vertical and horizontal dimensions of both atria were measured as perpendicular major and minor axes.

Right ventricular (RV) basal dimension was measured as the largest diameter in the basal third of the right ventricle in end-diastole. Tricuspid annular plane systolic excursion (TAPSE) was measured from dedicated M-mode recordings.

Tissue Doppler recording was made on the septal and lateral sides of the mitral annulus and on the tricuspid annulus using dedicated pulsed wave tissue Doppler acquisitions. Peak systolic velocity was denoted s'.

\section{Statistical analysis}

Continuous values are summarized using median with 25 th to 75 th percentile and categorical variables using proportions. The Mann-Whitney $U$ test and Chi-square test were used to compare baseline variables and Wilcoxon signed-rank test to compare 2D and M-mode measurements. Reference values for normality and degrees of abnormality were calculated using multivariate quantile regression with age and gender as predictors. Limit of normality was defined as 5th or 95th percentile of the respective value in the healthy subset. Gender specific cut-offs are provided for all variables and age-specific cut-offs are presented in variables where the testing showed relevant age 
differences. We stratified degrees of abnormality using the whole population sample including both healthy and remaining patients. Cut-offs for moderate abnormality were 2.5th or 97.5th interval of the whole sample and severe abnormality as 1st or 99th percentile of the whole sample. These differences are summarized in Fig. 2. Nonparametric methods with quantile regression were preferred because of non-normal distribution of echocardiographic variables (Shapiro-Wilks test $p<0.001$ for all echocardiographic variables for both healthy and general populations). Using cutoffs based on distribution of general population has been suggested previously $[4,5]$. A $p$ value $<0.05$ was considered significant. Analysis was done using $\mathrm{R}$ software version 3.0.2 (R Foundation for Statistical Computing, Vienna, Austria).

\section{Results}

\section{Baseline variables}

Overall, as Table 1 shows, the healthy cohort was on average younger, with a higher percentage of females and lower body weight, height, body surface area (BSA), body mass index (BMI), systolic and diastolic blood pressure. Healthy patients also had lower total cholesterol and triglycerides and higher HDL cholesterol and showed a numeric trend towards lower LDL levels. All patients in both subsets were Caucasians. The distribution of BSA, height and weight according to age groups is shown in Additional file 2: Table S9.

\section{Effects of age, gender and measurement method}

Tables 2 and 3 show the effects of gender and age on reference limits (the 5th or 95th percentile of healthy population). Values stratified by age and gender as well as effect of age and gender on median values are shown in Additional file 1: Tables S5 and S6, Additional file 2: Tables S7 and S8. Overall, there was a slight trend towards smaller LV size upper reference limits with increasing age. LV diameter upper reference limits decreased with age when measured using the $2 \mathrm{D}$ method. End-diastolic and end-systolic volume upper reference limit overall decreased with age. Longitudinal LV systolic function lower reference limit measured by s' significantly decreased. There was a strong tendency of LV mass and LV wall thickness upper reference limit to increase with age in the healthy cohort both using Mmode and 2D calculations and different indexations. There seemed to be an overall numeric trend towards enlargement of LA upper reference limit with age, significant in indexed LA diameter. Indexed right atrial

Table 3 Effects of age and gender on reference limits - left atrium, right chambers, aorta

\begin{tabular}{|c|c|c|c|c|}
\hline Variable & Age effect (per 10 years) & $\begin{array}{l}\text { Age effect } \\
p \text { value }\end{array}$ & Gender effect (male vs. female) & $\begin{array}{l}\text { Gender effect } \\
p \text { value }\end{array}$ \\
\hline \multicolumn{5}{|l|}{ Left atrium } \\
\hline LA diameter M-mode (mm) & $0.7[-0.2,1.7]$ & 0.138 & $4.3[2.1,6.6]$ & $<0.001$ \\
\hline LA diameter M-mode, BSA $\left(\mathrm{mm} / \mathrm{m}^{2}\right)$ & $1.0[0.5,1.4]$ & $<0.001$ & $-1.3[-2.2,-0.3]$ & 0.009 \\
\hline LA vertical diameter (mm) & $-0.2[-1.4,1.0]$ & 0.752 & $4.2[0.2,8.2]$ & 0.042 \\
\hline LA horizontal diameter (mm) & $1.1[-0.0,2.3]$ & 0.056 & $1.6[-1.0,4.2]$ & 0.232 \\
\hline LA volume (ml) & $1.1[-2.7,5.0]$ & 0.571 & $15.4[4.0,26.9]$ & 0.008 \\
\hline LA volume, BSA (ml/m²) & $1.6[-0.3,3.5]$ & 0.097 & $0.2[-4.8,5.3]$ & 0.924 \\
\hline \multicolumn{5}{|l|}{ Right ventricle } \\
\hline RV basal diameter (mm) & $0.9[-0.2,1.9]$ & 0.109 & $6.9[3.7,10.0]$ & $<0.001$ \\
\hline RV basal diameter, BSA $\left(\mathrm{mm} / \mathrm{m}^{2}\right)$ & $0.4[-0.0,0.9]$ & 0.066 & $0.1[-1.0,1.2]$ & 0.839 \\
\hline Tricuspid s' (m/s) & $-0.2[-0.6,0.2]$ & 0.261 & $-0.7[-1.6,0.3]$ & 0.194 \\
\hline TAPSE (mm) & $-0.6[-1.5,0.2]$ & 0.144 & $-0.0[-2.3,2.2]$ & 0.992 \\
\hline \multicolumn{5}{|l|}{ Right atrium } \\
\hline RA vertical diameter (mm) & $-0.0[-0.7,0.7]$ & 1.000 & $5.7[4.1,7.3]$ & $<0.001$ \\
\hline RA horizontal diameter (mm) & $-0.5[-1.4,0.3]$ & 0.202 & $6.3[4.3,8.3]$ & $<0.001$ \\
\hline RA vertical diameter, BSA $\left(\mathrm{mm} / \mathrm{m}^{2}\right)$ & $0.6[0.1,1.0]$ & 0.009 & $-1.6[-2.4,-0.8]$ & $<0.001$ \\
\hline RA horizontal diameter, BSA $\left(\mathrm{mm} / \mathrm{m}^{2}\right)$ & $0.1[-0.4,0.6]$ & 0.663 & $-0.5[-1.8,0.8]$ & 0.443 \\
\hline \multicolumn{5}{|l|}{ Aorta } \\
\hline Aortic root (mm) & $0.8[-0.1,1.8]$ & 0.084 & $5.5[3.4,7.7]$ & $<0.001$ \\
\hline Aortic root, BSA $\left(\mathrm{mm} / \mathrm{m}^{2}\right)$ & $0.4[0.0,0.8]$ & 0.045 & $-0.3[-1.2,0.7]$ & 0.589 \\
\hline
\end{tabular}

Values depict effect size on reference limit (95th or 5th percentile of the healthy subset) with $95 \%$ confidence interval $B S A$ body surface area, $L A$ left atrium, $R A$ right atrium, $R V$ right ventricle, TAPSE tricuspid annular plane systolic excursion 
vertical dimension and indexed aortic root diameter upper reference limits increased significantly with age.

LV diameter reference limits were larger in males, but this finding was completely reversed when indexed for BSA. In contrast, both end-systolic and end-diastolic LV volumes limits remained larger in males despite indexation. LV mass upper reference limit was also larger in males. Males had a significantly larger non-indexed RV basal diameter upper reference limit by over $6 \mathrm{~mm}$, a trend that disappeared after BSA indexation to BSA.

Overall, M-mode derived LV linear measurements were significantly larger compared to their 2D counterparts ( $p<0.001$ for all comparisons). An example of such discrepancy is shown in Fig. 3. Furthermore, BSAindexed LV mass using M-mode was significantly higher compared to the $2 \mathrm{D}$ method $(p<0.001)$.

\section{Estimated cut-off values}

General reference values for normality irrespective of age are shown in Tables 4 and 5 separated by gender. For variables significantly affected by age, we provide further age-related cut-offs in Additional file 1: Tables S1-S4. Parametric summaries including stratification by age and gender are included in Additional file 1: Tables S5 and S6, Additional file 2: Tables S7 and S8. As for LV mass and LA volume, distributions with reference limits are shown in Additional file 1: Figure S1 to give a clearer visual idea of their distribution. Furthermore, for LV mass, Additional file 1: Figure S2 summarizes differences due to age, gender, measurement technique and population subset.

\section{Discussion}

In our study, we calculated reference limits for chamber dimensions and systolic function of the left and right ventricles using a pre-specified healthy subset from a population-wide epidemiological survey. Furthermore, data from our unselected general population sample allowed us to propose cut-offs for mild, moderate and significant abnormality, based on the approach using predefined percentiles and unselected population sample $[4,5]$. The major strengths of our study are the homogeneity of the studied population, which was randomly selected and is considered representative of the Czech population, and analysis performed by skilled operators trained to use a standardized measurement technique.

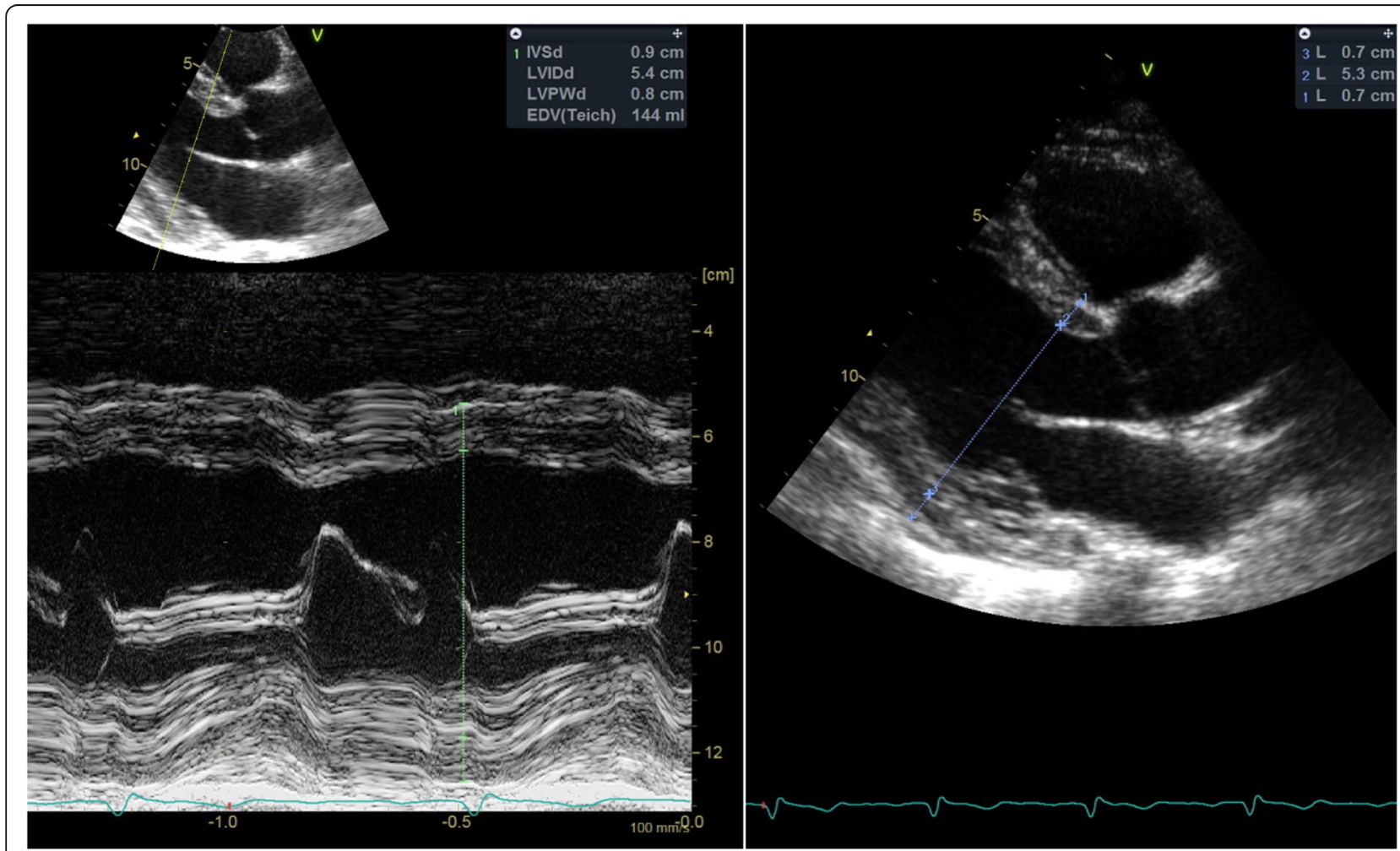

Fig. 3 This image in parasternal long-axis view illustrates some limitations of the M-mode method of measuring LV dimension and wall thickness in some patients. In the M-mode image on the left, an oblique cut leads to multiple problems. First is incorrect measurement of interventricular septum and possible confounding from right ventricular trabeculations. Furthermore, the posterior wall is difficult to measure due to many trabeculations in the basal part of the ventricle and this leads to possibly incorrect measurement. Also, the LV dimension was slightly larger with M-mode measurement. 2D imaging on the left side can achieve a proper geometric cut and slightly smaller wall thickness measurements. The yellow dotted line on the left image has been added to make the M-mode cut line more clearly visible 
Table 4 Reference limits for left ventricular measurements

\begin{tabular}{|c|c|c|c|c|c|c|}
\hline \multirow[t]{2}{*}{ Variable } & \multicolumn{3}{|l|}{ Males } & \multicolumn{3}{|l|}{ Females } \\
\hline & Abnormal & $\begin{array}{l}\text { Moderately } \\
\text { abnormal }\end{array}$ & $\begin{array}{l}\text { Severely } \\
\text { abnormal }\end{array}$ & Abnormal & $\begin{array}{l}\text { Moderately } \\
\text { abnormal }\end{array}$ & $\begin{array}{l}\text { Severely } \\
\text { abnormal }\end{array}$ \\
\hline \multicolumn{7}{|l|}{ LV dimensions } \\
\hline \multicolumn{7}{|l|}{ 2D method } \\
\hline LV end-diastolic diameter (mm) & $>56$ & $>60$ & $>63$ & $>51$ & $>56$ & $>58$ \\
\hline LV end-diastolic diameter, BSA $\left(\mathrm{mm} / \mathrm{m}^{2}\right)$ & $>28$ & $>30$ & $>31$ & $>30$ & $>31$ & $>32$ \\
\hline \multicolumn{7}{|l|}{ M-mode method } \\
\hline LV end-diastolic diameter (mm) & $>60$ & $>64$ & $>66$ & $>55$ & $>59$ & $>63$ \\
\hline VLV end-diastolic diameter, BSA $\left(\mathrm{mm} / \mathrm{m}^{2}\right)$ & $>31$ & $>32$ & $>33$ & $>32$ & $>33$ & $>34$ \\
\hline LV end-systolic diameter (mm) & $>40$ & $>44$ & $>49$ & $>36$ & $>39$ & $>41$ \\
\hline LV end-systolic diameter, BSA $\left(\mathrm{mm} / \mathrm{m}^{2}\right)$ & $>20$ & $>21$ & $>23$ & $>21$ & $(>21)^{a}$ & $(>23)^{a}$ \\
\hline \multicolumn{7}{|l|}{ LV mass and wall thickness } \\
\hline \multicolumn{7}{|l|}{ 2D method } \\
\hline Interventricular septum (mm) & $>11.5$ & $>14.0$ & $>15.0$ & $>10.3$ & $>12.3$ & $>13.3$ \\
\hline Posterior wall (mm) & $>10.7$ & $>12.3$ & $>13.0$ & $>9.3$ & $>11.0$ & $>11.7$ \\
\hline LV mass, BSA $\left(\mathrm{g} / \mathrm{m}^{2}\right)$ & $>107$ & $>130$ & $>138$ & $>82$ & $>111$ & $>128$ \\
\hline \multicolumn{7}{|l|}{ M-mode method } \\
\hline Interventricular septum (mm) & $>12.7$ & $>14.3$ & $>15.0$ & $>11.0$ & $>12.7$ & $>13.7$ \\
\hline Posterior wall (mm) & $>11.0$ & $>13.3$ & $>14.0$ & $>9.7$ & $>11.5$ & $>12.3$ \\
\hline LV mass, BSA $\left(\mathrm{g} / \mathrm{m}^{2}\right)$ & $>122$ & $>147$ & $>167$ & $>104$ & $>129$ & $>141$ \\
\hline LV mass, height $2.7(\mathrm{~g} / \mathrm{m})$ & $>53$ & $>68$ & $>76$ & $>47$ & $>69$ & $>76$ \\
\hline \multicolumn{7}{|l|}{ LV volumes and function } \\
\hline LV end-diastolic volume (ml) & $>150$ & $>181$ & $>205$ & $>109$ & $>136$ & $>157$ \\
\hline LV end-diastolic volume, BSA $\left(\mathrm{ml} / \mathrm{m}^{2}\right)$ & $>73$ & $>85$ & $>94$ & $>63$ & $>73$ & $>85$ \\
\hline LV end-systolic volume (ml) & $>69$ & $>81$ & $>99$ & $>44$ & $>56$ & $>71$ \\
\hline LV end-systolic volume, BSA (ml/m²) & $>33$ & $>39$ & $>46$ & $>25$ & $>30$ & $>37$ \\
\hline LV ejection fraction (\%) & $<50$ & $<46$ & $<42$ & $<53$ & $<50$ & $<47$ \\
\hline Mitral septal s' (cm/s) & $<6.0$ & $<5.0$ & $<4.3$ & $<6.0$ & $<5.0$ & $<4.3$ \\
\hline Mitral lateral s' (cm/s) & $<6.3$ & $<5.0$ & $<4.3$ & $<6.0$ & $<5.3$ & $<5.0$ \\
\hline
\end{tabular}

Mildly abnormal is defined as $>95$ th or $<$ th percentile of the healthy subset, moderately abnormal as $>97.5$ th or $<2.5$ th percentile and severely abnormal as $>99$ th or $<1$ st percentile of the whole sample

$B S A$ body surface area, $L V$ left ventricle

${ }^{a}$ Not recommended due to negligible difference between the healthy subset and general population, see Limitations

\section{Relation of normal values to age}

We used age-specific subgrouping in selected variables. This is consistent with current studies reporting normal values [2, 9]. Previously, age was intentionally not included in some analyses due to the uncertainty whether these effects represent true physiological aging [5]. However, a significant age effect was observed for several measurements in our and previous studies of normal populations [9-12]. Not correcting for age would lead to a large proportion of older patients without any apparent cardiovascular disease to fall outside the normal reference range.

\section{Reference limits for degrees of abnormality}

Although several recent studies have defined the upper reference limits for many echocardiographic parameters $[2,9,10]$, studies defining degrees of abnormality above this range are scarce [5]. In the absence of long-term prognostic data, a sample of the general population including patients with disease and using predefined percentiles is one of the possible approaches [4]. In our study, we had a general population sample, which allowed us to propose cut-offs using this methodology. These cut-offs are most relevant in variables where disease is prevalent in the general population, as is LV mass due to arterial 
Table 5 Reference limits for left atrium, right chambers and aorta

\begin{tabular}{|c|c|c|c|c|c|c|}
\hline \multirow[t]{2}{*}{ Variable } & \multicolumn{3}{|l|}{ Males } & \multicolumn{3}{|l|}{ Females } \\
\hline & Abnormal & $\begin{array}{l}\text { Moderately } \\
\text { abnormal }\end{array}$ & $\begin{array}{l}\text { Severely } \\
\text { abnormal }\end{array}$ & Abnormal & $\begin{array}{l}\text { Moderately } \\
\text { abnormal }\end{array}$ & $\begin{array}{l}\text { Severely } \\
\text { abnormal }\end{array}$ \\
\hline \multicolumn{7}{|l|}{ Left atrium } \\
\hline LA diameter M-mode $(\mathrm{mm})$ & $>46$ & $>53$ & $>56$ & $>41$ & $>48$ & $>51$ \\
\hline LA diameter $\mathrm{M}$-mode, BSA $\left(\mathrm{mm} / \mathrm{m}^{2}\right)$ & $>23$ & $>25$ & $>27$ & $>24$ & $>26$ & $>27$ \\
\hline LA vertical diameter (mm) & $>61$ & $>67$ & $>71$ & $>56$ & $>61$ & $>63$ \\
\hline LA horizontal diameter (mm) & $>48$ & $>52$ & $>54$ & $>46$ & $>50$ & $>54$ \\
\hline LA volume (ml) & $>86$ & $>108$ & $>123$ & $>70$ & $>90$ & $>105$ \\
\hline LA volume, BSA $\left(\mathrm{ml} / \mathrm{m}^{2}\right)$ & $>42$ & $>52$ & $>59$ & $>40$ & $>48$ & $>53$ \\
\hline \multicolumn{7}{|l|}{ Right ventricle } \\
\hline RV basal diameter (mm) & $>46$ & $>47$ & $>48$ & $>39$ & $>42$ & $>43$ \\
\hline RV basal diameter, BSA $\left(\mathrm{mm} / \mathrm{m}^{2}\right)$ & $>23$ & $(>23)^{a}$ & $(>24)^{a}$ & $>23$ & $(>24)^{\mathrm{a}}$ & $(>24)^{\mathrm{a}}$ \\
\hline Tricuspid s' (m/s) & $<9.0$ & $<8.0$ & $<7.0$ & $<9.0$ & $<8.0$ & $<7.7$ \\
\hline TAPSE (mm) & $<19$ & $<17$ & $<15$ & $<19$ & $<18$ & $<17$ \\
\hline \multicolumn{7}{|l|}{ Right atrium } \\
\hline RA vertical diameter (mm) & $>57$ & $>61$ & $>65$ & $>51$ & $>56$ & $>58$ \\
\hline RA horizontal diameter (mm) & $>50$ & $(>50)^{a}$ & $(>53)^{a}$ & $>42$ & $>45$ & $>47$ \\
\hline RA vertical diameter, BSA $\left(\mathrm{mm} / \mathrm{m}^{2}\right)$ & $>28$ & $>30$ & $>32$ & $>30$ & $>31$ & $>33$ \\
\hline RA horizontal diameter, BSA $\left(\mathrm{mm} / \mathrm{m}^{2}\right)$ & $>25$ & $(>25)^{\mathrm{a}}$ & $(>26)^{a}$ & $>25$ & $>26$ & $>27$ \\
\hline \multicolumn{7}{|l|}{ Aorta } \\
\hline Aortic root (mm) & $>40$ & $>42$ & $>43$ & $>34$ & $>36$ & $>37$ \\
\hline Aortic root, BSA (mm/m2) & $>19$ & $>20$ & $>21$ & $>20$ & $>21$ & $>22$ \\
\hline
\end{tabular}

Mildly abnormal is defined as $>95$ th or $<5$ th percentile of the healthy subset, moderately abnormal as $>97.5$ th or $<2.5$ th percentile and severely abnormal as $>99$ th or $<1$ st percentile of the whole sample

$B S A$ body surface area, $L A$ left atrium, $R A$ right atrium, $R V$ right ventricle, TAPSE tricuspid annular systolic plane excursion

${ }^{a}$ Not recommended due to negligible difference between the healthy subset and general population, see Limitations

hypertension. In these instances, degrees of abnormality can provide a sense of how extreme abnormal values are in a similar sense to degrees of abnormality provided in EACVI/ASE guidelines, which in some cases rely on multiples of standard deviation [1]. In other cases, low prevalence of disease in the general population makes difference between healthy and general populations negligible and these cut-offs only hypothesis-generating.

For some variables, most notably for LV ejection fraction and LA volume, cut-offs based on prognosis are well established and probably more useful $[13,14]$.

\section{LV dimensions, mass and wall thickness}

We found similar cut-offs for both indexed and nonindexed LV end-diastolic dimensions compared to current recommendations [15]. Interestingly, our study shows a clinically relevant overestimation of dimension and wall thickness using M-mode imaging compared to the $2 \mathrm{D}$ method. This is an intriguing finding conflicting with some previous reports [16]. It is most strikingly shown in our LV mass measurement, where our Mmode derived cut-offs were higher than the currently recommended cut-off values $\left(95\right.$ and $115 \mathrm{~g} / \mathrm{m}^{2}$ for men and women, respectively) by almost $10 \mathrm{~g} / \mathrm{m}^{2}$, while the 2D-derived limits were lower to a similar extent [15]. This can be visually appreciated in Additional file 1: Figures S1 and S2 and underscores the critical need to consider the measurement technique when evaluating LV mass. To the best of our knowledge, our study is the first to identify separate cut-offs for M-mode and 2D-derived LV mass derived from data obtained in such a large population sample. Furthermore, cut-offs for LV mass values significantly increased with age in our population, along with wall thickness. This trend has been shown in previous studies for both mass $[9,10]$ and wall thickness $[10,11]$. Whether this phenomenon represents a genuine effect of aging or confounding by other factors associated with increasing age is impossible to differentiate based on our data [17].

\section{$\mathrm{LV}$ volumes and systolic function}

Our LV volume cut-offs in apical views are similar to the current recommendations [1]. Ejection fraction cutoff was slightly lower than previously reported, but the known trend towards higher EF in females was numerically present in our population. Longitudinal systolic 
function assessed by s' is in general consistent with values presented previously [18].

\section{LA volume, RV diameter and function}

Left atrial volume reference limits were higher than the commonly accepted limit of $34 \mathrm{ml} / \mathrm{m}^{2}$ [4]. Epidemiological method of sampling our population could lead to these larger reference limits. Interestingly, our results are quite comparable to the more recently published NORRE data, that have shown an upper reference limit of $40.3 \mathrm{ml} / \mathrm{m}^{2}$ for both genders using the same methodology [9].

Right ventricular basal dimension was strongly dependent on gender, a significant difference not highlighted in the current recommendations, but shown in recent population studies $[9,10]$. Interestingly, indexation to BSA was able to abolish this difference and a cut-off value of $23 \mathrm{~mm} / \mathrm{m}^{2}$ seems reasonable as a sex-independent upper reference limit. A lower reference limit for TAPSE in our population was slightly higher than previously reported. Indexed right atrial diameters seemed comparable to previous recommendations [4].

\section{Limitations}

A significant limitation of our study is the absence of deformation indices. Despite that, routine chamber evaluation is still often done using relatively simple techniques described in our paper.

Another limitation is that defining degrees of abnormality based on percentiles of the general population is mostly relevant when prevalence of pathology is sufficient in the general population, as is the case for LV mass. When there is a small number of patients with disease, we observed small to no differences in cut-offs differentiating mild, moderate and severe abnormality, especially in young patients where overall cardiovascular disease prevalence is low. In these cases, these limits should be used carefully, if at all. To address this issue, wherever the degrees of abnormality are too small and converged, we have reported that in the Result tables. Furthermore, absence of prognostic data is a limitation based on design of the Czech post-MONICA survey; however, a crosssectional design is an established methodology for deriving normative values [15].

Simple indexing by BSA might be considered a limitation. However, it is the most commonly used indexation in echocardiography. Further analysis of anthropometric relations was beyond the scope of this manuscript.

\section{Conclusions}

This analysis reports echocardiographic reference values for chamber dimensions and ventricular systolic function gained from the population-based Czech post-MONICA study, providing unique normative ranges applicable to Central European populations. The age and gender dependence of echocardiographic variables is described, as well as differences between M-mode and 2D imaging. Furthermore, cut-offs for mild, moderate and severe abnormalities based on percentiles of the general population are provided where feasible.

\section{Supplementary information}

Supplementary information accompanies this paper at https://doi.org/10. 1186/s12947-019-0172-0.

\begin{abstract}
Additional file 1: Figure S1. Shows distribution of LV mass (both using M-mode and 2D imaging) and indexed LA volume distribution in both healthy and general cohort. It can be seen that distributions of most variables are significantly skewed. Furthermore, reference limits based on 95th percentile of normal population and 97.5th and 99th percentile of general populations are shown with points and annotated with values. Horizontal axis has been truncated at $150 \%$ of the 99th percentile of general population. Gaussian kernel density estimates are used for plotting. BSA, body surface area; LV, left ventricle. Figure S2. Showing distribution of indexed LV mass using different measurement methods by age and gender. Reference limits based on gender and age derived from quantile regression are shown. Severe abnormality is above 99th percentile of general population, moderate 97.5th - 99th percentile of general population and mild between 95th percentile of the healthy population and 97.5th percentile of general population. One female outlier from general population with LV mass over $250 \mathrm{~g}$ was excluded from the plotting but is included in the analyses. BSA, body surface area; LV, left ventricle. Table S1. Female reference limits by age - left ventricle. Table S2. Female reference limits by age - atria and aortic root. Table S3. Male reference limits by age - left ventricle. Table S4. Male reference limits by age - atria and aortic root. Table S5. Echocardiographic parameters for healthy population - left ventricle. Table S6. Echocardiographic parameters for healthy population - left atrium, right chambers and aorta.
\end{abstract}

Additional file 2: Table S7. Echocardiographic parameters for healthy population by gender and age - left ventricle. Table S8.

Echocardiographic parameters for healthy population by gender and age

- left atrium, right chambers and aorta. Table S9. Anthropometric

variables for healthy population by age and gender.

\section{Abbreviations}

BMI: Body mass index; BSA: Body surface area; LA: Left atrium; LV: Left ventricle; RV: Right ventricle; TAPSE: Tricuspid annular plane systolic excursion

\section{Acknowledgments}

Not applicable.

\section{Authors' contributions}

$\mathrm{RC}$ and $\mathrm{AL}$ conceived the overall design of the study and supervised both analysis of the data and writing of the manuscript. JCL, PK, LG and EN performed the measurements, collected the data and aided in writing the manuscript. JM performed the measurements, collected and analyzed the data, and wrote the manuscript. All authors read and approved the final manuscript.

\section{Funding}

The study was supported by grant No. 15-27109A (provided by the Ministry of Health of the Czech Republic) and by PROGRES Q38/LF1 (an institutional research funding project of Charles University, Prague, Czech Republic).

\section{Availability of data and materials}

The data that support the findings of this study are available on reasonable request from the corresponding author, Linhart $A$. The data are not publicly available due to the containing information that could compromise the privacy of research participants. 


\section{Ethics approval and consent to participate}

All participants signed informed consent and the study was approved by the joint ethics committee of the Institute for Clinical and Experimental Medicine and Thomayer Hospital, Prague and was in accordance with the Declaration of Helsinki.

\section{Consent for publication}

Not applicable - no individual patient data presented.

\section{Competing interests}

The authors declare that they have no competing interests.

\section{Author details}

'2nd Department of Medicine - Department of Cardiovascular Medicine, First Faculty of Medicine, Charles University and General University Hospital in Prague, U Nemocnice 2, 12808 Praha 2, Czech Republic. ${ }^{2}$ Center for Cardiovascular Prevention, First Faculty of Medicine, Charles University in Praque and Thomayer Hospital, Prague, Czech Republic.

Received: 8 July 2019 Accepted: 4 October 2019

Published online: 30 October 2019

\section{References}

1. Lang RM, Badano LP, Mor-Avi V, Afilalo J, Armstrong A, Ernande L, Flachskampf FA, Foster E, Goldstein SA, Kuznetsova T, Lancellotti P, Muraru D, Picard MH, Rietzschel ER, Rudski L, Spencer KT, Tsang W, Voigt JU. Recommendations for cardiac chamber quantification by echocardiography in adults: an update from the American Society of Echocardiography and the European Association of Cardiovascular Imaging. J Am Soc Echocardiogr. 2015;28:1-39 e14.

2. EchoNoRMAL Collaboration. Ethnic-specific normative reference values for echocardiographic LA and LV size, LV mass, and systolic function: the EchoNoRMAL study. JACC Cardiovasc Imaging. 2015;8:656-65.

3. Poppe KK, Bachmann ME, Triggs CM, Doughty RN, Whalley GA. Geographic variation in left ventricular mass and mass index: a systematic review. J Hum Hypertens. 2012;26:420-9.

4. Lang RM, Bierig M, Devereux RB, Flachskampf FA, Foster E, Pellikka PA Picard MH, Roman MJ, Seward J, Shanewise JS, Solomon SD, Spencer KT, Sutton MS, Stewart WJ. Recommendations for chamber quantification: a report from the American Society of Echocardiography's Guidelines and Standards Committee and the Chamber Quantification Writing Group. J Am Soc Echocardiogr. 2005;18:1440-63.

5. Vasan RS, Larson MG, Levy D, Evans JC, Benjamin EJ. Distribution and categorization of echocardiographic measurements in relation to reference limits: the Framingham Heart Study: formulation of a height- and sexspecific classification and its prospective validation. Circulation. 1997;96: 1863-73.

6. Cifkova R, Skodova Z, Bruthans J, Adamkova V, Jozifova M, Galovcova M, Wohlfahrt P, Krajcoviechova A, Poledne R, Stavek P, Lanska V. Longitudinal trends in major cardiovascular risk factors in the Czech population between 1985 and 2007/8. Czech MONICA and Czech post-MONICA. Atherosclerosis. 2010;211:676-81.

7. Cifkova R, Skodova Z, Bruthans J, Holub J, Adamkova V, Jozifova M, Galovcova M, Wohlfahrt P, Krajcoviechova A, Petrzilkova Z, Lanska V. Longitudinal trends in cardiovascular mortality and blood pressure levels, prevalence, awareness, treatment, and control of hypertension in the Czech population from 1985 to 2007/2008. J Hypertens. 2010;28:2196-203.

8. Devereux RB, Alonso DR, Lutas EM, Gottlieb GJ, Campo E, Sachs I, Reichek N. Echocardiographic assessment of left ventricular hypertrophy: comparison to necropsy findings. Am J Cardiol. 1986;57:450-8.

9. Kou S, Caballero L, Dulgheru R, Voilliot D, De Sousa C, Kacharava G, Athanassopoulos GD, Barone D, Baroni M, Cardim N, Gomez De Diego JJ, Hagendorff A, Henri C, Hristova K, Lopez T, Magne J, De La Morena G, Popescu BA, Penicka M, Ozyigit T, Rodrigo Carbonero JD, Salustri A, Van De Veire N, Von Bardeleben RS, Vinereanu D, Voigt JU, Zamorano JL, Donal E, Lang RM, Badano LP, Lancellotti P. Echocardiographic reference ranges for normal cardiac chamber size: results from the NORRE study. Eur Heart J Cardiovasc Imaging. 2014;15:680-90.

10. Daimon M, Watanabe H, Abe $Y$, Hirata $K$, Hozumi T, Ishii K, Ito H, Iwakura K, Izumi C, Matsuzaki M, Minagoe S, Abe H, Murata K, Nakatani S, Negishi K, Yoshida K, Tanabe K, Tanaka N, Tokai K, Yoshikawa J. Normal values of echocardiographic parameters in relation to age in a healthy Japanese population: the JAMP study. Circ J. 2008:72:1859-66.

11. Pfaffenberger S, Bartko P, Graf A, Pernicka E, Babayev J, Lolic E, Bonderman D, Baumgartner H, Maurer G, Mascherbauer J. Size matters! Impact of age, sex, height, and weight on the normal heart size. Circ Cardiovasc Imaging. 2013;6:1073-9.

12. Vasan RS, Larson MG, Benjamin EJ, Levy D. Echocardiographic reference values for aortic root size: the Framingham Heart Study. J Am Soc Echocardiogr. 1995;8:793-800.

13. Benjamin EJ, D'Agostino RB, Belanger AJ, Wolf PA, Levy D. Left atrial size and the risk of stroke and death. The Framingham Heart Study. Circulation. 1995;92:835-41

14. Yeboah J, Rodriguez CJ, Stacey B, Lima JA, Liu S, Carr JJ, Hundley WG, Herrington DM. Prognosis of individuals with asymptomatic left ventricular systolic dysfunction in the multi-ethnic study of atherosclerosis (MESA). Circulation. 2012;126:2713-9.

15. Lang RM, Badano LP, Mor-Avi V, Afilalo J, Armstrong A, Ernande L, Flachskampf FA, Foster E, Goldstein SA, Kuznetsova T, Lancellotti P, Muraru D, Picard MH, Rietzschel ER, Rudski L, Spencer KT, Tsang W, Voigt JU. Recommendations for cardiac chamber quantification by echocardiography in adults: an update from the American Society of Echocardiography and the European Association of Cardiovascular Imaging. Eur Heart J Cardiovasc Imaging. 2015;16:233-70

16. Ilercil A, O'Grady MJ, Roman MJ, Paranicas M, Lee ET, Welty TK, Fabsitz RR, Howard BV, Devereux RB. Reference values for echocardiographic measurements in urban and rural populations of differing ethnicity: the Strong Heart Study. J Am Soc Echocardiogr. 2001;14:601-11.

17. Dannenberg AL, Levy D, Garrison RJ. Impact of age on echocardiographic left ventricular mass in a healthy population (the Framingham Study). Am J Cardiol. 1989;64:1066-8.

18. Dalen $H$, Thorstensen $A$, Vatten $\amalg$, Aase $S A$, Stoylen A. Reference values and distribution of conventional echocardiographic Doppler measures and longitudinal tissue Doppler velocities in a population free from cardiovascular disease. Circ Cardiovasc Imaging. 2010;3:614-22.

\section{Publisher's Note}

Springer Nature remains neutral with regard to jurisdictional claims in published maps and institutional affiliations.

Ready to submit your research? Choose BMC and benefit from:

- fast, convenient online submission

- thorough peer review by experienced researchers in your field

- rapid publication on acceptance

- support for research data, including large and complex data types

- gold Open Access which fosters wider collaboration and increased citations

- maximum visibility for your research: over $100 \mathrm{M}$ website views per year

At $\mathrm{BMC}$, research is always in progress.

Learn more biomedcentral.com/submission 